\title{
Recurrent granular cell tumor: a case report and review of literature
}

\author{
Aditendraditya Singh Bhati ${ }^{1}$, Aarjun Tyagi ${ }^{2}$, Sudheer K. Tyagi ${ }^{1}$ \\ ${ }^{1}$ Department of Neurosurgery, Indraprastha Apollo Hospital, Sarita Vihar, New Delhi, India; ${ }^{2}$ Hamdard Institute of Medical Sciences \& Research, \\ New Delhi, India \\ Correspondence to: Dr. Aditendraditya Singh Bhati. Department of Neurosurgery, Indraprastha Apollo Hospital, Sarita Vihar, New Delhi 110076, \\ India. Email: adityaneurosurgery@yahoo.com.
}

\begin{abstract}
Granular cell tumors (GCTs) in the spine are uncommon. They are mostly located in the intradural extramedullary space and rarely, in an intramedullary (IM) location. Complete resection is the treatment of choice. Recurrences are rare in intradural-intramedullary (IDEM) GCTs. Recurrent and incompletely excised cases are subjected to adjuvant radiation therapy. We report such a recurrence in a 13-year-old girl who was re-operated and subjected to radiotherapy.
\end{abstract}

Keywords: Granular cell tumor (GCTs); intradural extramedullary tumors; recurrent spine tumors

Submitted Mar 05, 2017. Accepted for publication Jul 14, 2017.

doi: 10.21037 /jss.2017.08.01

View this article at: http://dx.doi.org/10.21037/jss.2017.08.01

\section{Introduction}

Granular cell tumors (GCTs) are rarely associated with the spine. They are soft tissue tumors mostly located on the tongue and the skin involving the upper limbs and trunk (1). Clinically, they manifest similar to spine tumors in the intradural-intramedullary (IDEM) location. Radiologically, they are similar to meningiomas and neurofibromas and are confirmed with histology. Only 14 cases involving the spine have been reported in literature (Table 1). We report a case of a 13-year-old girl with D12-L1 recurrent IDEM GCT, who was re-operated and subjected to radiotherapy, along with review of the literature. The purpose of reporting this case is because of the rarity of such tumors and its recurrence in the IDEM space, which has not been reported in literature. However, recurrences in intramedullary (IM) GCTs have been reported. Complete surgical excision is the treatment of choice. Recurrent and incompletely excised cases are subjected to radiotherapy.

\section{Case presentation}

A 13-year-old young girl was operated for D12-L1 tumor 7 months back at another hospital. The histopathological report was suggestive of GCT and immunohistochemistry was strongly positive for S-100 and many were CD 68 positive, with the Mib-1 labeling index being low (1-2\%). No adjuvant therapy was given following the surgery. She presented to us with lower backache radiating to both lower limbs, intermittent numbness of limbs, straining while urinating and constipation for the last 6 months. She had left lower limb weakness of $4 / 5$ for hip, knee and plantar flexion along with hypoesthesia involving the left L4, 5 \& S1 dermatomes. MRI dorso-lumbar spine revealed well defined lesion involving D12-L1 measuring $3.5 \mathrm{~cm} \times 1.5 \mathrm{~cm}$, which was iso-intense on $\mathrm{T} 1$, of variable intensity on $\mathrm{T} 2$ and displayed uniform enhancement on post contrast imaging in the IDEM space along with previous D11 \& 12 laminectomy changes (Figure 1). She underwent exploration of dorso-lumbar spine, and a partial L1 laminectomy was performed and the dura was opened. The tumor was well defined, capsulated, soft to firm, non-suckable, avascular and attached to the conus and L1 nerve root on the left antero-lateral aspect of the cord in the IDEM location. Piecemeal excision of the tumor was done. Thin sheath of the tumor adherent to conus and L1 nerve root was left. Postoperatively, she had weakness of the left hip flexor. Her weakness improved with physiotherapy and she able 

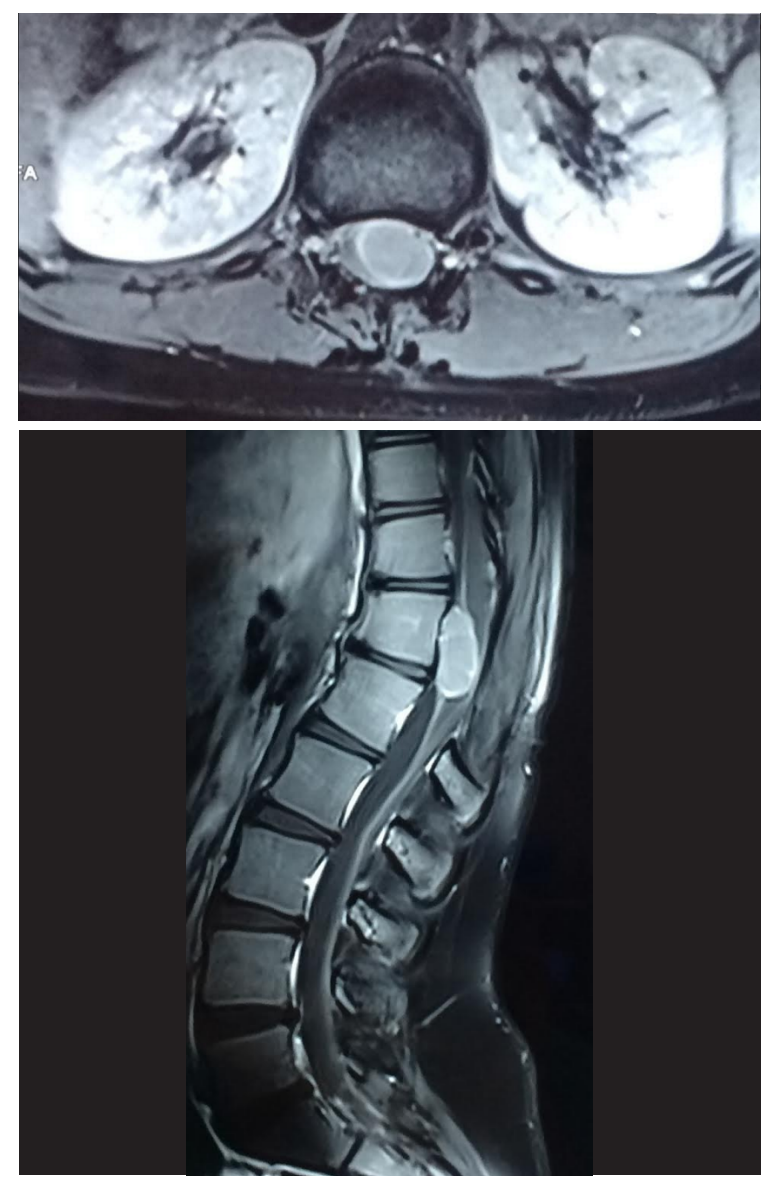

Figure 1 Contrast MRI lumbo-sacral spine showing uniformly enhancing intradural-intramedullary tumor involving D12-L1.

to walk with support. She was discharged on the $4^{\text {th }}$ postoperative day. Her histopathological report revealed GCT (Figure 2). She received radiotherapy in view of recurrence and incomplete excision and she is being followed up.

\section{Discussion}

GCTs of the spine are rare tumors. It was first reported in 1854 by Weber and later in 1926 by Abrikossoff, who described it as granular cell myoblastoma (15). Immunohistochemistry shows S-100 positivity, suggestive of Schwann cell origin (16). They have female preponderance and are mostly found in the younger age group (Table 1). They mostly involve the dorso-lumbar spine followed by cervical and less commonly, the sacro-coccygeal segments of spine. These are benign tumors and malignant transformation occurs only in $<2 \%$ of these tumors $(17,18)$

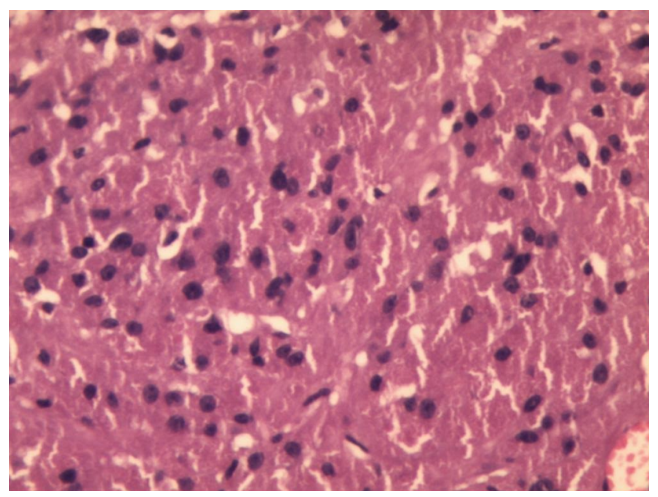

Figure 2 Microphotograph shows a mesenchymal tumor comprised of diffuse sheets of closely packed large round to polygonal cells containing abundant granular eosinophilic cytoplasm and centrally placed uniform round nuclei (10x).

and have been reported in soft tissue GCTs.

Immunohistochemistry of these tumors were strongly S-100 positive (Figure 2). Literature review shows they have a low proliferative index $(<3 \%)$. Apart from our case (Mib index $<1-2 \%)$, Pj et al. (12) and Vaghasiya et al. (13) did Mib index sampling which were very low $(<1-3 \%$ and $<1 \%$ respectively), suggesting benign nature of the tumor.

Complete surgical excision is the treatment of choice $(19,20)$. However, incomplete excision requires regular clinico-radiological follow-up and adjuvant radiotherapy. Recurrence is to be dealt with surgery followed by radiation therapy (7).

Literature review shows that these tumors involving the spine are mostly IDEM and rarely IM in location (Table 1). There were only three IM GCTs reported. Critchley et al. (6) and Burton et al. (7) have excised IM tumors and had recurrences, which were subjected to radiotherapy. However, Brown et al. (11), in 2015 operated on a 13-year-old young girl for C5 nerve root tumor extending into the central canal. It was managed by core biopsy in view of the risk of post-operative neurological deficits and the patient is being followed up. $\mathrm{Pj}$ et al. (12) operated on an extradural GCT at the level of T5T6 which was completely excised with no recurrence.

IDEM tumors are amenable for complete excision as compared to IM GCTs. This suggests that most of the IDEM GCTs are not densely adherent to the thecal sac or the existing nerve root. In comparision, IM tumors involve cord substance itself and hence pose the risk of incomplete excision. The recurrence is secondary to incomplete excision because of attachment to the surrounding glial 


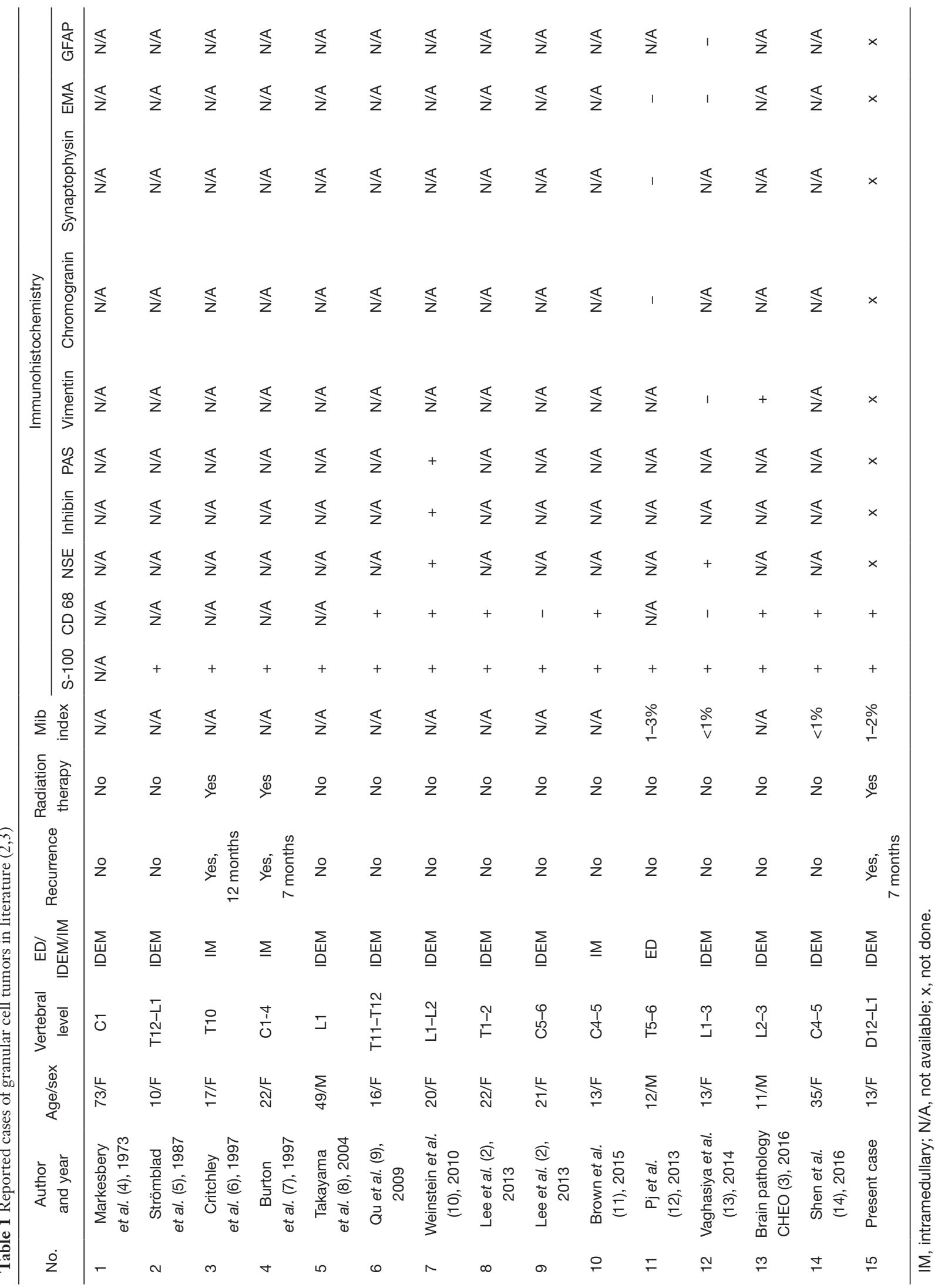


tissue, thecal sac or nerve root. Extradural GCTs are amenable for complete excision.

Literature review shows that there were no recurrences in IDEM GCTs. In the present case, patient had recurrence 7 months after surgery which is very rare considering its IDEM location. The extent of tumor excision of the previous surgery was unavailable, although the location of the tumor, which involved the conus and cauda (L1 nerve root), poses the possibility of incomplete tumor excision, causing the recurrence. GCTs with incomplete excision and recurrence definitely require clinico-radiological followup, re-surgery and/or radiotherapy. In our case, the patient had early recurrence and was re-operated and subjected to radiotherapy.

\section{Conclusions}

GCTs are rare benign tumors of spine and mostly involve the IDEM space and are amenable for complete excision. Recurrence is mostly seen in IM GCTs due to incomplete excision. Recurrence of GCTs involving IDEM space is probably due to its dense attachment to the thecal sac, nerve root or both. Complete excision is the treatment of choice. Incomplete excision and or recurrence are subjected to radiotherapy.

\section{Acknowledgements}

None.

\section{Footnote}

Conflicts of Interest: The authors have no conflicts of interest to declare.

Informed Consent: Written informed consent was obtained from the patient for publication of this manuscript and any accompanying images.

\section{References}

1. Ordóñes NG, Mackay B. Granular cell tumors: A review of the pathology and histogenesis. Ultrastruc Pathol 1999;23:207-22.

2. Lee CH, Hyun SJ, Lee JW, et al. Granular cell tumor of the intradural extramedullary spinal cord: report of two cases with respect to radiological differential diagnosis. J
Korean Neurosurg Soc 2013;53:121-4.

3. Brain Pathology Case of the Month - June 2016. Available online: http://path.upmc.edu/divisions/neuropath/bpath/ cases/case334.html

4. Markesbery WR, Duffy PE, Cowen D. Granular cell tumors of the central nervous system. J Neuropathol Exp Neurol 1973;32:92-109.

5. Strömblad LG, Brun A, Cameron R, et al. Spinal granular cell tumor with subarachnoid hemorrhage: case report. Neurosurgery 1987;21:230-3.

6. Critchley GR, Wallis NT, Cowie RA. Granular cell tumor of the spinal cord: case report. Br J Neurosurg 1997;11:452-4.

7. Burton BJ, Kumar VG, Bradford R. Granular cell tumor of the spinal cord in patient with Rubenstein-Taybi syndrome: case report: Br J Neurosurg 1997;11:257-9.

8. Takayama Y, Hasuo K, Takahashi N, et al. Granular cell tumor presenting as an intradural extra-medullary tumor. Clin Imaging 2004;28:271-3.

9. Qu J, Ma J, Luo L, et al. Subdural granular cell tumor in thoracic vertebral canal. Neurol India 2009;57:679-81.

10. Weinstein BJ, Arora T, Thompson LD. Intradural, extramedullary spinal cord granular cell tumor: a case report and clinicopathologic review of the literature. Neuropathology 2010;30:621-6.

11. Brown KG, Rao PJ, Oo TH, et al. Granular cell tumors of the spinal canal: intramedullary case report and a review of the literature. J Spine Surg 2015;1:94-8.

12. $\mathrm{Pj} \mathrm{T}$, Timothy $\mathrm{M}$. Granular cell tumor presenting as a pediatric spinal deformity. Harvard Orthopaedic J 2013:15.

13. Vaghasiya VL, Nasit JG, Parikh PA, et al. Intradural spinal granular cell tumor. Asian J Neurosurg 2014;9:96-8.

14. Shen U, Wang $S$, Shao $X$, et al. Intraspinal granular cell tumor: a case report and review of literature. Int $\mathrm{J}$ Clin Exp Pathol 2016;9:4013-20.

15. Muscardin LM, Paradisi M, Provini A, et al. Multiple cutaneous granular cell tumors, joint hypermobility and mild facial dysmorphism in a child. Int J Dermatol 2006;45:847-50.

16. Seo IS, Azzarelli B, Warner TF, et al. Multiple visceral and cutaneous granular cell tumors. Ultrastructural and immunocytochemical evidence of Schwann cell origin. Cancer 1984;53:2104-10.

17. Fanburg-Smith JC, Meis-Kindblom JM, Fante R, et al. Malignant granular cell tumor of soft tissue: Diagnostic criteriav and clinicopathologic correlation. Am J Surg Pathol 1998;22:779-94.

18. al-Sarraf M, Loud AV, Vaitkevicius VK. Malignant 
granular cell tumor. Arch Pathol 1971;91:550-8.

19. Sheithauer BW, Woodruff JM, Spinner RJ. Peripheral Nerve Sheath Tumors. In: Perry A, Bratt DJ. editors. Practical Surgical Neuropathology: A diagnostic approach, Chapter 12. Philadelphia: Churchill Livingstone Elsevier, 2010:235-85.
20. Weinstein BJ, Arora T, Thompson LD. Intradural, extramedullary spinal cord granular cell tumor: A case report and clinicopathologic review of the literature. Neuropathology 2010;30:621-6.

Cite this article as: Bhati AS, Tyagi A, Tyagi SK. Recurrent granular cell tumor: a case report and review of literature. J Spine Surg 2017;3(3):484-488. doi: 10.21037/jss.2017.08.01 